\title{
A POLARIZAÇÃO E A INTOLERÂNCIA NO ESTADO DEMOCRÁTICO DE DIREITO
}

\section{POLARIZATION AND INTOLERANCE IN THE DEMOCRATIC STATE OF LAW}

\section{Flávia Laurindo da Rosa ${ }^{1}$}

Resumo: O presente artigo trata da análise da polarização e da intolerância em um Estado Democrático de Direito, com ênfase no momento social contemporâneo, consubstanciado na sociedade brasileira. $\mathrm{O}$ objetivo principal dessa reflexão é fomentar uma cultura baseada na valorização de conquistas sociais, com a relevância da democracia em um país, de forma colaborativa com a justiça e com a sociedade. Ainda, após a delimitação sintética dos campos disciplinares aplicáveis, o presente texto destaca a importância da liberdade de expressão em um Estado Democrático de Direito para que diferentes concepções sejam debatidas em um cotejo analítico, com respeito aos participantes de um processo dialético.

Palavras-chave: Polarização. Intolerância. Estado Democrático de Direito.

Abstract: This article deals of the analysis of polarization and intolerance in the Democratic State of Law, with emphasis on the contemporary social moment, embodied in Brazilian society. The main objective of this reflection is to foster a culture based on valuing social achievements, with the promotion of democracy in a country, in a collaborative

1. Flávia Laurindo da Rosa; Especialista em Direito Público pela Universidade do Sul de Santa Catarina - UNISUL, com convênio com a Escola Superior da Magistratura no Estado de Santa Catarina - ESMESC. Pós-Graduanda em Direito Constitucional pela Academia Brasileira de Direito Constitucional - ABDConst. Bacharela em Direito pela Universidade do Sul de Santa Catarina - UNISUL.Atualmente, estagiária de pós-graduação no Ministério Público do Estado de Santa Catarina. E-mail: flavialaurindodarosa@gmail.com. 
way with justice and society. Still, after the synthetic delimitation of the applicable disciplinary fields, the present text highlights the importance of liberty of the expression in the Democratic State of Law, so that different conceptions are debated in the analytical collation, with respect to the participants of the dialectical process.

Keywords: Polarization. Intolerance. Democratic State.

\section{INTRODUÇÃO}

Este artigo apresenta uma reflexão inicial sobre a polarização e a intolerância em um Estado Democrático de Direito, de forma prejudicial à democracia, especialmente diante da divisão política em uma sociedade.

O presente ensaio está dividido em três partes. A primeira parte está destinada a apresentar, brevemente, uma contextualização da democracia no Brasil, embasando o histórico da sociedade atual.

A segunda parte dedica-se à análise dos discursos de intolerância e sua expansão na política brasileira, que se, hoje, têm como o principal foco de tensão no país.

Já a terceira seção pretende alinhar algumas contribuições históricas sobre as conquistas sociais no Brasil, com um viés a propiciar melhor adequação da democracia com as demandas submetidas ao poder judiciário em razãoda urgência na valorização do Estado Democrático de Direito.

Para tanto, utilizou-se o método de abordagem dedutivo, com a observância dos argumentos gerais presentes na sociedade. As ações instrumentais da pesquisa e seus métodos de procedimento condizem com o método de abordagem histórico, observando-se as consequências que a expansão da intolerância trouxe em determinados momentos fundamentais.

Para proceder com a análise da polarização, utilizou-se a pesquisa bibliográfica com materiais já publicados, como livros, periódicos e publicações em mídias digitais. Já para a pesquisa documental, utilizou-se a legislação constitucional, acrescida de jurisprudência. 


\section{DEMOCRACIA NO BRASIL}

O Estado Democrático de Direito, de maneira geral, está vinculado à ideia da soberania popular no sentido de cooperação de indivíduos em um determinado âmbito, instituída a partir do voto, diante da necessidade de estabelecer um modo comum de participação social para a formação da vontade estatal.

Entende-se que o Estado Democrático de Direito:

deve proporcionar condições efetivas aos cidadãos de escolher entre participar direta ou indiretamente da formação das decisões coletivas, exercendo os seus direitos de liberdade, de expressão, de reunião e de associação. Além do exercício efetivo de direitos que viabilizam a inserção do homem na vida política (PENA; OLIVEIRA, 2020, p. 2).

Nesse viés, esse Estado garante o respeito às liberdades civis, ou seja, o respeito pelos direitos humanos e pelas garantias fundamentais, ressaltando-se o respeito à dignidade da pessoa humana.

Ainda, há uma finalidade do Estado para coibir abusos do aparato estatal para com os indivíduos, pelo que se limita o poder do Estado sobre eles, já que os direitos fundamentais lhes conferem autonomia e liberdade. Em suma, as próprias autoridades políticas estão sujeitas ao respeito das regras de direito.

O Estado Democrático de Direito superou o conceito de Estado de Direito, já que houve uma abrangência das garantias fundamentais. Assim, no que se refere à cooperação por meio do voto, tem-se, na Constituição da República, que a soberania popular será exercida pelo sufrágio universal e pelo voto, que é direto e secreto, com valor igual para todos (BRASIL, 1988).

A função da Constituição em um Estado Democrático, para Barroso (2018, p. 67), divide-se em duas. A primeira função é para veicular consensos mínimos e essenciais à dignidade das pessoas, com reflexo no funcionamento do regime democrático, que não deve ser afetado por políticas ocasionais. E a segunda função é para garantir o espaço 
próprio do pluralismo político e, consequentemente, assegurar o mecanismo democrático.

Em razão disso, a participação social assume relevânciapor se tratar da garantia da vontade e do bem-estar social. Segundo Diniz (2019):

Podemos pensar em duas categorias simples de participação social: “institucional" e "não-institucional”. A primeira se trata de procedimentos organizados pelo próprio Estado (as eleições para cargos políticos, por exemplo) e a segunda de procedimentos mais espontâneos, organizados pela sociedade em si (passeatas de movimentos sociais) (grifo no original).

Sabe-se que essa participação pode acontecer de inúmeras formas, seja por meio de comunicação social, com opinião pública, até demandas de movimentos sociais que exigem representatividade.

Assim, a concepção do Estado Democrático de Direito é amplamente difundida. A esse propósito:

Suas principais características são soberania popular; da democracia representativa e participativa; um Estado Constitucional, ou seja, que possui uma constituição que emanou da vontade do povo; e um sistema de garantia dos direitos humanos (ENTENDA..., 2018).

Adentrando no tema da democracia, pode-se afirmar que, desde a criação do Estado Moderno, ela sempre esteve presente, de alguma forma, nos anseios dos indivíduos (POLAK, 2008, p. 8).

Para complementar, Polak (2008, p. 8) dispõe que:

os dois fundamentos básicos de uma sociedade democrática nunca abandonaram as mentes dos cidadãos de qualquer parte: os ideais de liberdade, consubstanciados nos direitos humanos, e de igualdade entre os indivíduos, formando uma sociedade que, embora não constituída por iguais, é pelo menos uma sociedade na qual todos os indivíduos são reconhecidos como cidadãos e gozam de direitos a uma vida digna, à saúde, educação, tendo a possibilidade de viver e não apenas sobreviver. (grifo no original).

Com a concepção instrumental do Estado, têm-se que as eleições e os seus respectivos eleitos são um termômetro para a condução da democracia no país. Entretanto, em uma pesquisa divulgada pela Revista 
Exame no ano de 2019, que ouviu 2.948 pessoas, concluiu que, no Brasil, "cresceu o número de pessoas que não consideram a democracia como a melhor forma de governo" (APOIO..., 2019).

Pode-se citar como os possíveis motivos para não se considerar a democracia como a melhor forma de governo os:

eleitos eternos, que acumulam ou alteram funções municipais, estaduais, legislativas ou ministeriais, e veem a população como o elo fundamental da representação dos interesses locais; governos que fazem eles mesmos as leis; representantes do povo maciçamente formados em certa escola de administração; ministros ou assessores de ministros realocados em empresas públicas ou semipúblicas; partidos financiados por fraudes nos contratos públicos; empresários investindo uma quantidade colossal de dinheiro em busca de um mandato; donos de impérios midiáticos privados apoderando-se do império das mídias públicas por meio de suas funções públicas. Em resumo: apropriação da coisa pública por uma sólida aliança entre a oligarquia estatal e a econômica. (RANCIÈRE, 2014, p. 93).

Com isso, há a caracterização do fim da democracia elencada por Runciman (2017, p. 7), que faz um alerta: "podemos nem sequer perceber que o fim está chegando porque estaremos olhando na direção errada".

$\mathrm{O}$ autor, quando dispõe sobre o fim da democracia, realiza alguns comentários, como, por exemplo:

O espaço entre o pessoal e o apocalíptico, que é onde tradicionalmente se desenvolve a política democrática, transformou-se num campo de batalha para visões de mundo rivais constituídas de expectativas pessoais ou apocalípticas do pior que pode acontecer. O que está faltando é uma política de nível médio. Em qualquer distribuição em forma de cauda longa, é a parte média a atingida com mais força. A democracia contemporânea não é uma exceção. Macroeventos e microexperiências (sic) ocupam todo o espaço e excluem a possibilidade de um meio-termo razoável. Quando as pessoas procuram instituições que poderiam facilitar essa intermediação, descobrem que foram esvaziadas pela pressão de inquietações e pelas frustrações políticas grandes demais ou pequenas demais para se ajustar a elas (RUNCIMAN, 2017, p. 191). 
Sobre o desvio de olhar mencionado anteriormente, pode-se entender pela desintegração das instituições democráticas, consoante dispõem Levitsky e Ziblatt (2018, p. 164) quando referem que se está:

abrindo um vazio desconcertante entre como nosso sistema político funciona e as expectativas há muito arraigadas de como ele deve funcionar. À medida que nossas grades flexíveis de proteção foram se enfraquecendo, nós nos tornamos cada vez mais vulneráveis a líderes antidemocráticos.

Como se vive atualmente em dois lados, Kalout (2020) apresenta um discurso oposto e otimista, em que a democracia irá continuar a existir e deve resistir. O autor arremata dispondo da forma de operar, que deve ser com "coragem e compromisso democrático, [...] se mais brasileiros animados desses sentimentos fizerem a voz ressoar, a democracia certamente não perecerá".

Entretanto, a divisão maniqueísta presente na sociedade brasileira afasta-se das suas características principais, quais sejam, "lhaneza no trato, a hospitalidade, a generosidade, virtudes tão gabadas por estrangeiros que nos visitam, representam, com efeito, um traço definido do caráter brasileiro" (HOLANDA, 1995, p. 146).

Na perspectiva de divisão do Estado é que se desenvolve os descontentamentos coletivos, voltado, por vezes, a relevar a violência na modernidade, com a utilização principalmente das mídias sociais. Segundo o projeto Comunica que Muda, divulgado em 2016, que analisou o conteúdo de aproximadamente 400 milsposts, foram retratados traços de intolerância em 97,4\% das postagens (SODRÉ, 2016).

Com relação ao discurso do ódio crescente nas plataformas disponibilizadas pela internet, principalmente nas redes sociais, pode-se dizer que, como o mundo virtual se tornou a ferramenta de interligação de pessoas, de todos os lugares do mundo, facilitando a interação social dos indivíduos, obteve-se que, de certa forma:

A possibilidade de anonimato e a velocidade na disseminação das mensagens via internet encoraja manifestações preconceituosas de todo tipo. Há uma sensação de poder e de impunidade que, em conjunto com a ignorância e o preconceito, além de outros sentimentos 
amalgamados, impulsiona o hatera destilar a sua ira, em velocidade digital (ANDRADE, 2019)

Por conseguinte, as redes sociais, de alguma forma, validam o ódio das pessoas, porque nelas é possível a sua expressão e, em razão disso, é possível receber aplausos de amigos e/ou seguidores, representado por compartilhamentos ou curtidas, dando uma dimensão pública do ato.

As redes sociais digitais, em sua configuração particular, explicitaram a emergência de produção e de circulação de enunciados de protesto (contrapalavra), portanto, situações de enfrentamento, lutas políticas e ideológicas. Evidencia-se, assim, o potencial dessas redes sociais de se constituírem como espaços contemporâneos para publicizar a produção dos próprios sujeitos envolvidos no evento como alternativa a outras mídias como, por exemplo, jornais e revistas, pertencentes às grandes empresas de comunicação que, por vezes, corroboram os interesses de uma classe hegemônica representante do discurso oficial (QUADRADO; FERREIRA, 2020).

O fortalecimento de um projeto de ódio, com ataques virtuais e divulgação de falsas notícias, instrumentaliza a intolerância no presente. Sabe-se que democracia e intolerância constituem situações antagônicas. Assim,

quem pensa diferente de mim não é meu inimigo, mas meu parceiro na construção de um mundo plural. A democracia tem lugar para conservadores, liberais e progressistas. Nela, só não há lugar para a intolerância, a desonestidade e a violência (EM DISCURSO..., 2020).

Registre-se que a disseminação da raiva e dos ataques nas redes sociais não é um fenômeno isolado da internet, mas sim um comportamento humano da vida real, que se manifesta, por vezes, em outra plataforma. Isso porque há uma linha tênue entre uma ameaça virtual e uma ação criminosa, em que claramente não se ampara no campo da liberdade de expressão.

Aliás, nesse panorama, elenca-se a liberdade de expressão como um importante instrumento jurídico para a compreensão da configuração do Estado. Sob a perspectiva de desenvolvimento social, é legítimo do 
processo democrático o desejo que o Poder instituído exerça a representação dos eleitores. Entretanto, isso não tem relação com a intolerância, que, para Dunker (2017, apud Vasconcellos, 2017), “deriva da falta de experiência no lugar comum, ou seja, não conseguir mais se comunicar, não compartilhar valores. Em suma, não conseguir fazer as diferenças naturais se tornarem algo produtivo".

A liberdade de expressão "é pilar fundamental de sustentação, condição essencial para a existência de uma verdadeira sociedade democrática" (PRETEL, 2010). Ela tem uma função de viabilizar e efetivar, portanto, a democracia em seus mais variados âmbitos. Para tanto, deve-se propiciar instrumentos normativos destinados a conter excessos para garantir, nas relações sociais, esse direito.

Isso porque, o direito à liberdade de expressão está intimamente ligado à natureza humana e, consequentemente, na forma de se relacionar em sociedade, propiciando o diálogo da população.

Contudo, atualmente existe um discurso introdutório do ódio. $\mathrm{O}$ discurso na política passou a ser um discurso não de criação ou de composição, mas de confronto. Cabe ressaltar que o processo democrático é um processo de administração do dissenso para resolver o consenso, e não para impô-lo.

\section{A INTOLERÂNCIA E A SUA EXPANSÃo}

Com o objetivo de demonstrar a intolerância e a polarização da democracia brasileira, importante a identificação de situações em que construíram, de certa forma, uma cultura de ódio no país.

Os motivos para a crescente intolerância são inúmeros, mas podem ser, principalmente, por questões ligadas à economia, à saúde, à descrença na política e, principalmente, à (in)segurança. Isso é o que se depreende da $138^{\mathrm{a}}$ pesquisa do CNT/MDA, que demonstrou as áreas que mais precisam de melhorias no Brasil. Os apontamentos por meio das entrevistas realizadas em 2018 foram: saúde com 73,4\%, educação com 45,6\% e segurança com 37,9\% (RESULTADOS..., 2018). 
Ainda, o Fórum Brasileiro de Segurança Pública (2016) divulgou que $57 \%$ da população acredita que "bandido bom é bandido morto". Sobre a dimensão dessa frase, deve-se atentar ao fato de qual bandido deve ser morto, uma vez que, segundo Baratta (1993, p. 50), há um paradoxo na identificação desse perfil:

[...] a sociologia jurídico-penal e a experiência cotidiana demonstram que o sistema direciona sua ação principalmente às infrações praticadas pelo segmento mais frágil e marginal da população; que os grupos poderosos na sociedade possuem a capacidade de impor ao sistema uma quase que total impunidade das próprias ações criminais.

Quando se define a vida de outrem em uma simples ação (evento morte), há um afastamento dos princípios democráticos amparados na Constituição da República Federativa do Brasil, principalmente o princípio da dignidade da pessoa humana, em que se mostra afastado por discursos que tem como justificativa o aumento da criminalidade e a insegurança no país.

O referido princípio significa, para Ricardo Souto (2019), "respeito à condição mínima de existência humana, um valor absoluto e constitucionalmente consagrado que consolida o respeito à pessoa humana".

Em virtude da importância desse princípio, cabe registrar outra consideração acerca dele, quando se tem que, em razão de sua existência, a dignidade da pessoa humana é atribuída às pessoas,

independentemente de suas circunstâncias concretas ou dos danos que eventualmente tenham causado à realidade externa, isto é, ela é também reconhecida aos mais cruéis criminosos, terroristas, ou a qualquer outra denominação que se queira atribuir aos indivíduos que violam os direitos dos seus semelhantes, pois eles são reconhecidos como pessoas e seus atos, por mais tenebrosos que sejam não são capazes de apagar esse traço inato (PADILHA; BERTONCINI, 2016).

Desse modo, a dignidade da pessoa humana é uma garantia da necessidade vital de todos os indivíduos, já que é um valor intrínseco, sendo um fundamento basilar da República Federativa do Brasil. 
Retomando os discursos de descontentamento com a política criminal no país, em que se ampara, principalmente, na impunidade de crimes (ou na sensação da impunidade), crescem, de forma exponencial, outras demandas, como os pedidos de pena de morte no Brasil. $\mathrm{O}$ apoio para essa medida cresceu entre os brasileiros, com 57\% favorável à pena de morte no ano de 2017. A pesquisa divulgada pelo Data Folha identificou que é "o maior índice da série histórica (iniciada em 1991) e, em comparação com a pesquisa anterior, de março de 2008, o índice cresceu 10 pontos (era 47\%)" (DATA FOLHA, 2017).

Registre-se quanto à questão da impunidade, que se trata de uma sensação, já que o Brasil é o terceiro país com a maior população carcerária do mundo, de tal forma que não se pode afirmar que, no país, as pessoas não vão presas.

Em 2019, o Brasil possuía 773.151 pessoas privadas de liberdade, em todos os regimes, consoante dados do Levantamento Nacional de Informações Penitenciárias - Infopen. (DEPEN..., 2020).

Sobre esse quadro no Brasil, os números anteriores mostram "que o país vive um movimento de superencarceramento e, o pior, a taxa é crescente". (SANTORO; TAVARES; GOMES, 2017).

As demandas por ações e implementações no país de medidas afastadas do conceito de dignidade da pessoa humana e sem conhecimento das necessidades práticas da sociedade civil acabam por desprezar, de certa forma, a dimensão da legislação constitucional e sua ideia de evolução, já que há a previsão de que "[...] não haverá penas: [...] de morte, salvo em caso de guerra declarada" (BRASIL, 1988).

O Estado deve ser entendido como uma categoria de coletividade, e não como um todo em si, isoladamente considerado, na medida em que não se pode admitir que um homem médio tome atitudes como: apedrejar menina de 11 (onze) anos de idade por seguir determinada religião (ZAREMBA, 2015); atacar com ofensas na internet uma apresentadora por ser negra ('MAJU'..., 2015); amarrar um suspeito de roubo em um poste e linchá-lo até à morte (SUSPEITO..., 2015); e, ainda, matar por homofobia, representada pelos crescentes assassinatos da população LGBT (SOUTO, L., 2018). 
Sobre o chamado "homem médio", esse se entende por um "homem razoável, que pondera a situação, cede e tenta encontrar a decisão mais justa possível" (BRASIL, 2017).

Deve-se refletir sobre essas ações, porque atacam justamente os grupos minoritários e vulneráveis, envolvendo questões ideológicas que perpassam o discurso de ódio, com os desdobramentos na esfera da ação, com intenso desrespeito, já que é oriundo de um comportamento odioso.

Conforme mencionado anteriormente, àquelas situações que até então eram tratadas apenas como virtuais passam a ocorrer inúmeras vezes no mundo real, com a diversificação do preconceito, da discriminação, representando a violência em um país de miscigenação sociocultural.

Além disso, considera-se um exemplo atual de intolerância aquele movimento em que pessoas foram às ruas pedir o fechamento do Congresso Nacional e do Supremo Tribunal Federal (ALVES, L., 2019).

Ainda nesse tema, Vidal e Silva (2019) dispõem que: "Cuida-se de discussão que exige um estudo crítico, por envolver questões como a crise de efetividade constitucional e a progressiva perda de legitimidade popular dos espaços deliberativos majoritários".

Os movimentos sociais estão amparados na Constituição e em seu próprio fundamento, tornando-se legítimo no processo democrático. Entretanto, o que se tem como ilógico é quando alguns indivíduos, utilizando desse meio disponível, muito em razão da democracia, requerem um retrocesso a ela.

Os direitos subjetivos de liberdades individuais devem conferir a plenitude dos direitos fundamentais, cunhando-se os elementos configuradores de um pluralismo político. Dessa forma, importante destacar a lição de Guterres (2019), que dispõe: "Para aqueles que insistem em usar o medo para dividir comunidades, devemos dizer: diversidade é uma riqueza, nunca uma ameaça".

O pluralismo político é encontrado no texto da Constituição, quando trata dos princípios fundamentais da República Federativa do Brasil, para garantir o respeito pela existência de várias opiniões, já que reco- 
nhece a multiplicidade da formação do Brasil, assegurando a liberdade de expressão.

Nesse sentido:

A partir do pluralismo também é reconhecido que a sociedade é estruturada por diferentes ideias, conceitos, atos, que a diversidade religiosa, de gênero, entre outras, são importantes e que os modos de vida devem ser garantidos e preservados, não importando quais sejam, desde que dentro dos impedimentos da lei. Dessa forma, ao ser reconhecido como um dos fundamentos da Constituição Federal, políticas públicas para a garantia do pluralismo devem sempre estar em constante elaboração (COELHO, 2019).

Dessa forma, é possível concluir que o pluralismo político é vigente no ordenamento jurídico brasileiro, por compreender a transitoriedade das relações sociais em razão da evolução da sociedade.

Ainda, em complemento:

O pluralismo político vem demarcado como último e importante fundamento do Estado Democrático de Direito brasileiro, sua relevância deriva do fato de que, para chegarmos à síntese das necessidades da sociedade, conveniente se faz que as diferentes vontades desta sociedade possam se expressar, defendendo seus pontos de vista, que serão avaliados e condensados pelo Estado. Portanto, denota-se que o conceito de pluralismo político engloba o de pluralismo partidário, que, conforme já dito, é importantíssimo para a manutenção da democracia. O pluralismo em questão está presente em todas as áreas da sociedade, por meio da existência de diversos sindicatos, igrejas representativas de múltiplas religiões, escolas, universidades, associações civis constituídas para a defesa do interesse de grupos da sociedade etc. (KAMMER, 2003, p. 8).

Nesse viés, há de ser compreendido, no âmbito do presente trabalho, que a intolerância e a polarização, de forma maniqueísta, com o preconceito e a vontade de excluir o outro, são exemplos de manifestações autoritárias, levadas a um contexto político, contrários à democracia.

A prática histórica de excluir os grupos vulneráveis ainda é praticada, e o descontentamento dos brasileiros com a situação política do país 
não pode ser ensejador ao ataque da liberdade de expressão, ao pluralismo político e à segurança jurídica do Estado Brasileiro.

\section{CONTRIBUIÇÕES HISTÓRICAS}

Para adentrar no presente capítulo, é necessário realizar alguns comentários acerca dos grupos vulneráveis, que, em dado momento histórico, se manifestaram e conquistaram reconhecimento.

Por minorias e grupos vulneráveis, entendem-se por aqueles que:

originam-se em relações de assimetria social (econômica, educacional, cultural etc.). Nessa perspectiva, minoria pode ser definida a partir de uma particularização de um grupo, já que a maioria se define por um agrupamento generalizado, ou seja, por um processo de generalização baseado na indeterminação de traços, os quais indicam um padrão de suposta normalidade, considerada majoritária em relação ao outro que destoar dele. A vulnerabilidade advém, pois, de pressões desse suposto padrão de normalidade, que pressiona tudo e todos que possam ser considerados diferentes. A violência, por sua vez, tanto pode ser física quanto simbólica, originária dessa pressão que, muitas vezes, na forma de preconceito e rejeição, marginaliza e discrimina o diferente. (CARMO, 2016, p. 5-6).

Diante disso, a situação de vulnerabilidade social relaciona-se com a exclusão de determinado grupo de pessoas, juntamente com a ausência de representatividade e oportunidades.

É possível citar como exemplo, portanto, mulheres, crianças, adolescentes, idosos, população pobre, moradores de rua, pessoas com deficiências e a própria comunidade LGBT, ou aqueles que estão em uma posição não dominante no Estado, como os índios, os quilombos e os ciganos.

Especificamente sobre a situação das crianças e dos adolescentes, têm-se que, com o advento da Constituição da República Federativa do Brasil, se tornaram detentores de direitos, e isso se deu pela participação da sociedade, na década de 1980, para expressar os interesses daqueles.

Isso é o que se conclui do seguinte trecho: 
Aproveitando o momento, organizações voltadas à infância começaram um conclame de toda a sociedade em prol da 'Emenda da Criança, Prioridade Nacional'. E, assim, crianças e adolescentes tomaram conta do Congresso Nacional, para entregar mais de um milhão de assinaturas coletadas. Os legisladores constituintes, demandados, aprovaram, por unanimidade, o art. 227. (OS FILHOS..., grifo no original).

Em razão disso, criou-se o Estatuto da Criança e do Adolescente para regulamentar àquele dispositivo constitucional, garantindo às crianças e aos adolescentes diversos direitos fundamentais.

O referido dispositivo constitucional, elenca que:

Art. 227. É dever da família, da sociedade e do Estado assegurar à criança, ao adolescente e ao jovem, com absoluta prioridade, o direito à vida, à saúde, à alimentação, à educação, ao lazer, à profissionalização, à cultura, à dignidade, ao respeito, à liberdade e à convivência familiar e comunitária, além de colocá-los a salvo de toda forma de negligência, discriminação, exploração, violência, crueldade e opressão. (BRASIL, 1988).

Da mesma forma, deu-se o Estatuto da Pessoa com Deficiência, que possui a acessibilidade universal como um eixo central, além de diversas outras regulamentações e reservas:

Art. $1^{\circ}$ É instituída a Lei Brasileira de Inclusão da Pessoa com Deficiência (Estatuto da Pessoa com Deficiência), destinada a assegurar e a promover, em condições de igualdade, o exercício dos direitos e das liberdades fundamentais por pessoa com deficiência, visando à sua inclusão social e cidadania. (BRASIL, 2015).

Como visto, é possível, por meio de manifestações sociais, modificar uma realidade até então imposta, e isso se trata de um processo de concessões mútuas. No Brasil, após a ditadura militar, diversos acontecimentos simbolizaram um processo de abertura política no país, antes mesmo da criação dos Estatutos elencados anteriormente, e um dos mais importantes para ser citado foi o movimento "Diretas Já". 
Esse movimento foi derivado de uma conquista popular, quando multidões foram às ruas clamar pelo voto direto para eleger o Presidente da República.

A luta pela normalização democrática e pela conquista do Estado Democrático de Direito começara assim que se instalou o golpe de 1964 e especialmente após o Ato Institucional n ${ }^{\circ} 5$, de 13.12.1968, que foi o instrumento mais autoritário da história política do Brasil. Tomara (sic), porém, as ruas, a partir da eleição dos Governadores em 1982. Intensificara-se, quando, no início de 1984, as multidões acorreram entusiásticas aos comícios em prol da eleição direta do Presidente da República, interpretando o sentimento da Nação, em busca do reequilíbrio da vida nacional, que só poderia consubstanciar-se numa nova ordem constitucional que refizesse o pacto político-social. (LIMA; PASSOS, 2013).

Ainda, o movimento relevou a presença da vontade por uma nova sociedade civil, de forma plural e participativa em que não mais aceitava ser objeto de militares, com o objetivo de tornar-se sujeito coletivo da história (REIS, 2010, p. 233).

Com relação à participação dos indivíduos na formação do Estado, Kelsen (2000, p. 109) dispõe que:

Uma vez que todos devem ser livres na maior medida possível, todos devem participar da formação da vontade do Estado e, conseqüentemente ( $\mathrm{sic}$ ), em idêntico grau. Historicamente a luta pela democracia é uma luta pela liberdade política, vale dizer pela participação do povo nas funções legislativa e executiva.

Abordando outros movimentos sociais, de extrema importância é a trajetória da mulher desde o ingresso na política, por isso merecedora de destaque. Os movimentos feministas elencam a luta de mulheres pela participação não só na política, mas no trabalho e na própria sociedade. Pellanda (2018, apud Sodré, 2018) alerta que "são ao menos 140 anos de história de luta pela participação política das mulheres no Brasil e ainda temos muito caminho a percorrer para a igualdade de gênero".

A história das mulheres possui um traço de busca por emancipação. De forma organizada, elas conquistaram (pelo menos nos textos legis- 
lativos) direitos essenciais, como a educação, a liberdade para escolher sua profissão, a possibilidade de votar e se candidatar (MAIS MULHER..., 2013, p. 12).

Entretanto, ainda carecem de maior amplitude, uma vez que as mulheres ainda são protagonistas de situações de desigualdade pela não efetivação dos direitos para o plano concreto (ROSA, 2020, p. 29-30).

Aliás, não só as mulheres, porque, voltando ao foco das crianças, é de conhecimento que o trabalho infantil ainda é uma realidade no país, afastando àqueles dispositivos de direitos e garantias, veja-se:

Em 2019, o Brasil tinha 1,8 milhão de crianças e adolescentes em situação de trabalho infantil. O número representa $4,6 \%$ desta população. [...] Percentualmente, $45,9 \%$ das crianças que trabalhavam estavam ocupadas em atividades perigosas em 2019. [...] 66,4\% das vítimas eram meninos e $66,1 \%$ eram pretos ou pardos. Entre as pessoas em situação de trabalho infantil, 53,7\% estavam no grupo de 16 e 17 anos de idade; $25 \%$ no grupo de 14 e 15 anos; e $21,3 \%$ no de 5 a 13 anos de idade. (ALVES, I.,2021).

Entretanto, espera-se uma evolução quanto a essas e outras questões, por meio do amparo aos anseios sociais, de que a Constituição de 1988 se baseou, uma vez que é um texto-base influenciado, por vários movimentos sociais que canalizaram suas expectativas, como o já citado movimento das Diretas Já, que exigia maior participação na vida democrática do país e que moldou, nesse ambiente, o conjunto de direitos que procurou consolidar a democracia no Brasil. (ROSA, 2020, p. 35).

É preciso resgatar aqueles anseios anteriormente dispostos e evoluí-los para o presente, aplicando com a conexão sobre o combate à intolerância, já que ela se apresenta real, e, por isso, há uma necessidade de implantar ideias de combate ao ódio, nutridas de discursos das diferenças, da laicidade do Estado, da democracia brasileira e da preservação da dignidade da pessoa humana.

Ao se tratar da Constituição da República Federativa do Brasil, Mello (2018, p. 4) relata que:

Ao lado da estruturação do poder e da limitação diante da soberania popular, o constituinte deu especial ênfase à disciplina dos direitos 
fundamentais, todos gravitando em torno da dignidade da pessoa humana. Sem tanta ambição científica, é um projeto político de resgate imediato da democracia, de afirmação permanente da liberdade e da igualdade, de transformação social a médio e longo prazos. É uma Constituição ousada, pretensiosa, mas passível de ser concretizada. Sem romantismo, tem-se uma história de êxito. Um projeto bem-sucedido!

Mayer (2008 apud Migalhas, 2008) dispõe que uma das maiores conquistas da Carta foi o estabelecimento do Estado Democrático de Direito:

O cidadão se sentiu seguro e protegido diante do Estado. Muita gente reclama por ser uma Carta muito detalhista. Mas isso é, de certa forma, muito bom, porque mais assuntos se tornaram constitucionais e realmente ajudaram na transformação histórica e social do Brasil.

No sistema jurídico brasileiro, compete ao STF - Supremo Tribunal Federal - zelar pelos direitos e pelas garantias individuais, permitindo o exercício direto da cidadania e consagrando os princípios do direito adquirido, do ato jurídico perfeito e da coisa julgada. Por isso, muitos o denominam como guardião da Constituição.

Como a judicialização foi mais acentuada no país, diante da Constituição Federal de 1988, buscando a inserção de direitos após a retomada da democracia, em um cenário que se tem ausência de políticas públicas efetivas ou soluções extrajudiciais para a resolução de conflitos, é utilizado o ativismo judicial para assegurar direitos e garantias fundamentais (ROSA, 2020, p. 41-42).

Existe um crescente número de demandas judiciais em todo o país, e, conforme divulgação do $\mathrm{CNJ}$, “o primeiro grau de jurisdição é o segmento mais sobrecarregado do Poder Judiciário e, por conseguinte, aquele que presta serviços judiciários mais aquém da qualidade desejada" (PRIORIZAÇÃO...).

Há um histórico no país de intensa judicialização, inserindo-se na cultura dos brasileiros. Isso também adveio com a Constituição de 1988, que proporcionou o acesso à justiça, que possui conceito e apli- 
cação amplamente difundido. Registre-se o comentário de como deve ser compreendido:

O Acesso à Justiça deve ser compreendido, assim, como o acesso obtido, alcançado, tanto por intermédio dos meios alternativos de solução de conflitos de interesses, quanto pela via jurisdicional e das políticas públicas, de forma tempestiva, adequada e eficiente, realizando uma ordem de valores fundamentais e essenciais que interessam a toda e qualquer pessoa. É a pacificação social com a realização do escopo da justiça. Em se tratando de jurisdição estatal, a cargo do Poder Judiciário, a tutela jurisdicional, a ser ministrada pelo Estado-juiz, deve ser voltada para a realização da justiça. É a justa composição do conflito de interesse ou da realização do direito violado ou ameaçado. (RUIZ, 2018, grifo no original).

Considerando a grande demanda de conflitos submetidos ao Poder Judiciário, juntamente com a ideia de acesso à justiça, e a morosidade também do Poder Legislativo, quando das legislações, uma vez que, muitas vezes, a realidade atual, com o advento da tecnologia e de novas formas de se relacionar e de se fazer obrigações, são diversas daquelas elencadas em lei, ou, diante da ausência de previsões, surge com força o termo de ativismo judicial.

Para Barroso (2018, p. 235):

A ideia de ativismo judicial está associada a uma participação mais ampla e intensa do Judiciário na concretização dos valores e fins constitucionais, com maior interferência no espaço de atuação dos outros dois Poderes. Em muitas situações, nem sequer há confronto, mas mera ocupação de espaços vazios.

Assim, o ativismo judicial entra em foco quando há um descolamento entre a classe política e a sociedade quando determinadas demandas sociais desejam ser atendidas de maneira efetiva. O Poder Judiciário, portanto, potencializa o texto constitucional para preencher as lacunas quando há omissões. Essa é uma tendência para expandir a proteção dos bens jurídicos tutelados pelo ordenamento jurídico, sobretudo os fundamentais, produzindo a eficácia da norma. 
Por derradeiro, sabe-se que os conceitos de Estado Democrático de Direito, Democracia e Acesso à Justiça se complementam de forma harmônica, porque somente terá acesso à ordem jurídica quem recebe a justiça. E recebê-la significa ser admitido em juízo e, além disso, com a participação não somente processual, mas também social, para que aquele provimento jurisdicional seja em conformidade com os valores da sociedade. Esses são os contornos do que se tem como um processo justo que todos desejam, uma vez que ele é composto pela efetividade das garantias previstas no ordenamento jurídico, com a disposição dos meios para atingir esses resultados.

\section{CONCLUSÃO}

A Constituição da República Federativa do Brasil de 1988, por meio de movimentos que canalizaram suas expectativas, oriundos de todos os segmentos da sociedade, é a representação da consolidação da democracia no país.

O texto constitucional que gravita em torno do princípio da dignidade da pessoa humana tem por intuito uma sociedade pluralista e sem preconceitos, e efetivar esses valores do Estado Democrático de Direito requer interações recíprocas entre as instituições.

A necessidade de uma reação institucional é veemente, pois a intolerância é antidemocrática e, por uma conclusão lógica, inconstitucional, uma vez que é incompatível com o Estado Democrático de Direito.

É curioso refletir que, em anos passados, as pessoas foram às ruas pela normalização democrática do país, com reivindicação de eleições diretas para eleição do Presidente da República, enquanto, na atualidade, se vê o oposto, com manifestações que requerem intervenção militar, fechamento do Congresso Nacional e, por consequência, a supressão das instituições fundantes do Estado Democrático de Direito no Brasil.

A intolerância é alimentada com acusações insensatas e bravatas virtuais, mas não encontra amparo no Estado Democrático de Direito, já que tolhe a liberdade de expressão, falseando a representação popular 
e, por consequência, os representantes passam a atender interesses não democráticos, o que se distancia da vontade real dos representados.

Historicamente, a luta pela democracia é, também, pela liberdade política, com a participação da população nas funções e/ou nos poderes do Estado, principalmente no Legislativo e Executivo. O contexto de lutas reafirma os valores relacionados com o Estado Democrático de Direito.

Entretanto, passadas décadas da promulgação da Constituição brasileira, constata-se que, para além das conquistas galgadas, há muito caminho para o Estado brasileiro percorrer, com vistas à implementação de efetivas políticas voltadas à sociedade.

O Poder Judiciário tem assumido grande protagonismo na implementação de ações estatais almejadas pela sociedade em diversas áreas de atuação do Estado, quando se mostram insuficiente pelos indivíduos. Assim, o aprofundamento dos preceitos democráticos, voltados à concretização das promessas constitucionais, é um caminho útil a ser trilhado para os próximos anos.

\section{REFERÊNCIAS}

ALVES, Isabela. Brasil tem 1,8 milhão de crianças em situação de trabalho infantil. Observatório do Terceiro Setor,13 jan. 2021. Disponível em: https://observatorio3setor.org.br/noticias/brasil-tem-1-8-milhao-de-criancas-em-situacao-de-trabalho-infantil/. Acesso em: 20 maio 2021.

ALVES, Letícia. Embora minoritários, ativistas pediram fechamento do Congresso e do STF. Poder 360,26 maio 2019. Disponível em: https:// www.poder360.com.br/governo/embora-minoritarios-ativistas-pediram-fechamento-do-congresso-e-do-stf/. Acesso em: 19 maio 2021.

ANDRADE, André Gustavo Corrêa de. O discurso de ódio na internet. 231. ed. JC - Justiça e Cidadania. 2019. Disponível em: https:// www.editorajc.com.br/o-discurso-de-odio-na-internet/. Acesso em: 19 maio 2021.

APOIO dos brasileiros à democracia diminuiu em 2019. Exame, jan. 2020. Disponível em: https://exame.com/brasil/apoio-a-democracia- 
-cai-no-primeiro-ano-do-governo-bolsonaro-diz-datafolha/.Acesso em: 26 mar. 2021.

BARATTA, Alessandro. Direitos Humanos: Entre a violência estrutural e a violência penal. Fac. de Ciênc. Penais, Porto Alegre, v. 6, n. 2, p. 44-61, abr/maio/jun. 1993.

BARROSO, Luis Roberto. Curso de direito constitucional contemporâneo: os conceitos fundamentais e a construção do novo modelo. 7 . ed. São Paulo: Saraiva, 2018.

BRASIL. [Constituição (1988)]. Constituição da República Federativa do Brasil. Brasília, DF: Presidência da República, 1988. Disponível em: http://www.planalto.gov.br/ccivil_03/constituicao/constituicao. htm. Acesso em: 25 mar. 2021.

BRASIL. Lei no 13.146, de 6 de julho de 2015. Institui a Lei Brasileira de Inclusão da Pessoa com Deficiência (Estatuto da Pessoa com Deficiência). 2015. Disponível em: http://www.planalto.gov.br/ccivil_03/_ ato2015-2018/2015/lei/113146.htm. Acesso em: 20 mai. 2021.

BRASIL. Tribunal de Justiça do Estado do Amazonas. Apelação Cível n. 0250487-19.2011.8.04.0001. Apelação Cível. Indenização por dano moral. Alegação de tratamento ríspido excedendo a educação e os bons costumes. Vítima concorreu para o evento danoso. Art. 945 do CC. "Teoria do Homem Médio". Banalização do instituto do dano moral. Apelo conhecido e não provido. Relator: Des. Airton Luís Corrêa Gentil. 01 de outubro de 2017. Disponível em: https://tjam.jusbrasil.com.br/jurisprudencia/525572387/2504871920118040001-am-0250487-1920118040001. Acesso em: 25 mar. 2021.

CARMO, Cláudio Márcio do. Grupos minoritários, grupos vulneráveis e o problema da (in)tolerância: uma relação linguístico-discursiva e ideológica entre o desrespeito e a manifestação do ódio no contexto brasileiro. Revista do Instituto de Estudos Brasileiros, n. 64, 2016. Disponível em: https:/www.scielo.br/pdf/rieb/n64/0020-3874-rieb-64-0201. pdf. Acesso em: 20 maio 2021. 
COELHO, Nuno Manuel Morgadinho dos Santos. Em Dia com o Direito \#3: A importância do pluralismo político. Jornal da USP,27 nov. 2019. Disponível em: https://jornal.usp.br/podcast/em-dia-com-o-direito-3-a-importancia-do-pluralismo-politico/. Acesso em: 20 maio 2021.

DATA FOLHA. Temas polêmicos. 28, 29 e 30 nov. 2017. Disponível em: http://media.folha.uol.com.br/datafolha/2018/01/08/b29e802ac9aa4689aa7d66fbcdc24a52e045d6de.pdf. Acesso em: 26 mar. 2021.

DEPEN atualiza dados sobre a população carcerária do Brasil. Ministério da Justiça e Segurança Pública,14 fev. 2020. Disponível em: https://www.gov.br/mj/pt-br/assuntos/noticias/depen-lanca-paineis-dinamicos-para-consulta-do-infopen-2019. Acesso em: 19 maio 2021.

DINIZ, Gabriel. Participação social: por que ela é tão importante para a gestão pública?. CLP - Centro de Liderança Pública. 18 fev. 2019. Disponível em: https://www.clp.org.br/participacao-social-por-que-ela-e-importante-para-a-gestao-publica-mlg2/. Acesso em: 18 maio 2021.

DUNKER, Christian, apud VASCONCELLOS, Mateus. Intolerância: um risco à democracia. Jan. 2017. Disponível em: https://observatorio3setor.org.br/carrossel/intolerancia-um-risco-a-democracia/. Acesso em: 26 mar. 2021.

EM DISCURSO de posse, ministro Luís Roberto Barroso defende conciliação e diálogo como metas para o Brasil. Tribunal Superior Eleitoral, 25 maio 2020. Disponível em: https://www.tse.jus.br/imprensa/noticias-tse/2020/Maio/em-discurso-de-posse-ministro-luis-roberto-barroso-defende-conciliacao-e-dialogo-como-metas-para-o-brasil. Acesso em: 26 mar. 2021.

ENTENDA o que é o Estado Democrático de Direito. Planalto, out. 2018. Disponível em: https://www2.planalto.gov.br/mandatomicheltemer/acompanhe-planalto/noticias/2018/10/entenda-o-que-e-o-estado-democratico-de-direito. Acesso em: 26 mar. 2021.

FÓRUM BRASILEIRO DE SEGURANÇA PÚBLICA. Anuário Brasileiro de Segurança Pública. São Paulo, 2016.Disponível em: https://fo- 
rumseguranca.org.br/storage/10_anuario_site_18-11-2016-retificado. pdf. Acesso em: 26 mar. 2021.

GUTERRES, António. As chamas do discurso do ódio. Nações Unidas Brasil, jul. 2019. Disponível em: https://unaids.org.br/2019/07/ as-chamas-do-discurso-do-odio-por-antonio-guterres/. Acesso em: 26 mar. 2021.

HOLANDA, Sérgio Buarque de. Raízes do Brasil. 26. ed. São Paulo: Companhia das Letras, 1995.

KALOUT, Hussein. A resistência e os limites da democracia brasileira. Época, 1 jun. 2020. Disponível em: https://epoca.globo.com/colunistas/ coluna-a-resistencia-os-limites-da-democracia-brasileira-24456519. Acesso em: 26 mar. 2021.

KAMMER, Iris. Considerações sobre o estado democrático de direito e os fundamentos da República Federativa do Brasil. Revista Jurídica "9 de Julho", São Paulo, n. 2, 2003. Disponível em: https://www. al.sp.gov.br/alesp/biblioteca-digital/obra/?id=496. Acesso em: 20 maio 2021.

KELSEN, Hans. A democracia. 2. ed. São Paulo: Martins Fontes, 2000.

LEVITSKY, Steven; ZIBLATT, Daniel. Como as democracias morrem. Zahar, 2018.

LIMA, João Alberto de Oliveira; PASSOS, Edilenice; NICOLA, João Rafael. A Gênese do Texto da Constituição de 1988. Brasília: Senado Federal,2 v. 2013. Disponível em: http://www.senado.leg.br/publicacoes/GeneseConstituicao/pdf/genese-cf-1988-1.pdf. Acesso em: 26 mar. 2021.

MAIS MULHER na Política, Mulher, tome partido! Brasília, 2013. Disponível em: https://www2.senado.leg.br/bdsf/bitstream/handle/ $\mathrm{id} / 496489 /$ livreto-mais-mulher-na-politica.pdf?sequence=1. Acesso em: 26 mar. 2021. 
'MAJU', do JN, é alvo de racismo nas redes sociais. Brasil 247, 3 jul. 2015. Disponível em: https://www.brasil247.com/midia/maju-do-jn-e-alvo-de-racismo-nas-redes-sociais. Acesso em: 25 mar. 2021.

MAYER, Rafael. 2008, apud MIGALHAS. Ministro Rafael Mayer relembra 1988.8 out. 2008. Disponível em: https://www.migalhas. com.br/quentes/70831/ministrorafael-mayer-relembra-1988. Acesso em: 26 mar. 2021.

MELLO, Marco Aurélio. 30 anos da Constituição Federal de 1988: uma história de sucesso. Disponível em:http://www.stf.jus.br/arquivo/ cms/noticiaNoticiaStf/anexo/30anosMMA.pdf. Acesso em: 26 mar. 2021.

OS FILHOS dos outros e os filhos de ninguém são nossa responsabilidade constitucional e moral. Prioridade Absoluta. Disponível em: https://prioridadeabsoluta.org.br/entenda-a-prioridade/. Acesso em: 20 maio 2021.

PADILHA, Elisângela; BERTONCINI, Carla. A dignidade da pessoa humana na teoria dos direitos fundamentais de Robert Alexy: uma análise sobre o seu caráter absoluto ou relativo na ordem jurídico-constitucional. Revista Brasileira de Direito, v. 12, n. 2, 2016. Disponível em: https://seer.imed.edu.br/index.php/revistadedireito/article/ view/1113/1057. Acesso em: 19 maio 2021.

PELLANDA, Andressa, apud SODRÉ, Mônica. A participação das mulheres na política no Brasil: o direito de votar, de sermos representadas e de participar da tomada de decisão.8 mar. 2018. Disponível em:https://politica.estadao.com.br/blogs/legis-ativo/a-participacao-das-mulheres-na-politica-no-brasil-o-direito-de-votar-de-sermos-representadas-e-de-participar-da-tomada-de-decisao/. Acesso em: 26 mar. 2021.

PENA, Luciana da Silva; OLIVEIRA, José Luiz de. Estado democrático de direito na perspectiva de Norberto Bobbio. Revista Vozes dos Vales: Publicações Acadêmicas da Universidade Federal dos Vales do Jequitinhonha e Mucuri - UFVJM, maio 2020. Disponível em: 
http://site.ufvjm.edu.br/revistamultidisciplinar/files/2020/06/Luciana. pdf. Acesso em: 18 maio 2021.

PRETEL, Guilherme. Liberdade de expressão. Notícias Paulistas,26 fev. 2010. Disponível em: https://www.oabsp.org.br/subs/santoanastacio/institucional/artigos-publicados-no-jornal-noticias-paulistas/liberdade-de-expressao. Acesso em: 19 maio 2021.

PRIORIZAÇÃO do $1^{\circ}$ Grau da Justiça. Conselho Nacional de Justiça. Disponível em: https://www.cnj.jus.br/programas-e-acoes/priorizacao-do-1o-grau/dados-estatisticos-priorizacao/. Acesso em: 20 maio 2021.

POLAK, Ana Luiza N. de Souza. O revisitar dos conceitos de democracia: da representação política à democracia participativa. Monografia (Setor de Ciências Jurídicas) - Faculdade de Direito, Universidade Federal do Paraná. Curitiba. 2008. Disponível em: https://acervodigital.ufpr.br/bitstream/handle/1884/31001/M\%201039.pdf? sequence=1. Acesso em: 18 maio 2021.

QUADRADO, Jaqueline Carvalho; FERREIRA, Ewerton da Silva. Ódio e intolerância nas redes sociais digitais. Rev. Katálysis, v. 23, n. 3, Florianópolis. set/dez, 2020. Disponível em: https://www.scielo.br/ scielo.php?script $=$ sci_arttext\&pid=S1414-49802020000300419. Acesso em: 19 maio 2021.

RANCIÈRE, Jacques. O ódio à democracia. São Paulo: Boitempo, 2014.

REIS, José Roberto Franco. O coração do Brasil bate nas ruas: a luta pela redemocratização do país. Disponível em:http://observatoriohistoria.coc.fiocruz.br/local/File/na-corda-bamba-cap_7.pdf.Acesso em: 26 mar. 2021.

RESUlTADOS da $138^{\mathrm{a}}$ Pesquisa CNT/MDA. CNT Transporte Atual,17 set. 2018. Disponível em: https://www.cnt.org.br/agencia-cnt/cnt-divulga-resultados-138-pesquisa-cnt-mda. Acesso em: 19 maio 2021.

ROSA, Flávia Laurindo da. A Democracia em tempos de intolerância. 2020. 
RUIZ, Ivan Aparecido. Princípio do acesso justiça. Tomo processo civil. 2018. Disponível em: https:/enciclopediajuridica.pucsp.br/verbete/201/edicao-1/principio-do-acesso-justica. Acesso em: 20 maio 2021.

RUNCIMAN, David. Como a democracia chega ao fim. Todavia, 2017.

SANTORO, Antonio Eduardo Ramires; TAVARES, Natália Lucero Frias; GOMES, Jefferson de Carvalho. A perspectiva dinâmica da população provisoriamente encarcerada no contexto do superencarceramento brasileiro. Instituto Brasileiro de Ciências Criminais, 1 nov. 2017. Disponível em: https://www.ibccrim.org.br/noticias/exibir/6774/. Acesso em: 19 maio 2021.

SODRÉ, Raquel. Intolerância online rompe com a ideia do brasileiro cordial. O Tempo, 18 set. 2016. Disponível em: https://www.otempo. com.br/interessa/intolerancia-onlinerompe-com-a-ideia-do-brasileiro-cordial-1.1373307. Acesso em: 26 mar. 2021.

SOUTO, Luiza. Assassinatos de LGTB crescem 30\% entre 2016 e 2017, segundo relatório. O Globo,17 jan. 2018. Disponível em: https:// oglobo.globo.com/sociedade/assassinatos-de-lgbt-crescem-30-entre-2016-2017-segundo-relatorio-22295785. Acesso em: 26 mar. 2021.

SOUTO, Ricardo dos Santos. A dignidade da pessoa humana como um valor absoluto no Brasil. Revista NUFEN, v.11, n. 3. Belém, set./dez. 2019. Disponível em: http://pepsic.bvsalud.org/scielo.php?script=sci_arttext\&pid=S2175-25912019000300011. Acesso em: 26 mar. 2021.

SUSPEITO de assalto é amarrado a poste e espancado até a morte no Maranhão. Gazeta do Povo,7 jul. 2015. Disponível em: https://www. gazetadopovo.com.br/vida-e-cidadania/suspeito-de-assalto-e-amarrado-a-poste-e-espancado-ate-a-morte-no-maranhao-edhb3jha0vvsdivs1tijheav9/. Acesso em: 26 mar. 2021.

VIDAL, Manuela; SANTOS, Silva Oliveira. O significado dos pedidos de fechamento do Congresso Nacional para a democracia brasileira. Revista Dizer, v. 4, n. 1, 31 dez. 2019. Disponível em: http://periodicos.ufc.br/dizer/article/view/43186. Acesso em: 19 maio 2021. 
ZAREMBA, Júlia. Vítima de intolerância religiosa, menina de 11 anos é apedrejada na cabeça após festa de Candomblé. Extra,16 jun. 2015. Disponível em: https://extra.globo.com/casos-de-policia/vitima-deintolerancia-religiosa-menina-de-11-anos-apedrejada-na-cabeca-apos-festa-de-candomble-16456208.html. Acesso em: 26 mar. 2021.

Recebido em: 01/04/2021

Aprovado em:10/08/2021 